\title{
Testing Usability and Feasibility of a Mobile Educator Tool for Pediatric Diabetes Self-Management: Mixed Methods Pilot Study
}

Marisa Otis ${ }^{1}$, MPH; Jack Zhu ${ }^{1}$, MPH; Suleiman N Mustafa-Kutana ${ }^{2}$, MD; Angelina V Bernier ${ }^{3}$, MD; Julio Ma Shum², BA; Arlette A Soros Dupre ${ }^{2}$, MD; Monica L Wang ${ }^{1}$, SCD, MS

\footnotetext{
${ }^{1}$ Department of Community Health Sciences, Boston University School of Public Health, Boston, MA, United States

${ }^{2}$ Division of Pediatric Endocrinology and Metabolism, Boston Medical Center, Boston, MA, United States

${ }^{3}$ Division of Pediatric Endocrinology, University of Florida, Gainesville, FL, United States
}

\section{Corresponding Author:}

Monica L Wang, SCD, MS

Department of Community Health Sciences

Boston University School of Public Health

Crosstown Center, 4th Floor

801 Massachusetts Avenue

Boston, MA, 02118

United States

Phone: 16174141357

Email: mlwang@bu.edu

\section{Abstract}

Background: Mobile interventions hold promise as an intervention modality to engage children in improving diabetes self-management education, attitudes, and behaviors.

Objective: This pilot study aimed to explore the usability, acceptability, and feasibility of delivering a mobile diabetes educational tool to parent-child pairs in a clinical setting.

Methods: This mixed methods pilot study comprised two concurrent phases with differing study participants. Phase 1 used user testing interviews to collect qualitative data on the usability and acceptability of the tool. Phase 2 used a single-arm pre- and poststudy design to quantitatively evaluate the feasibility and preliminary efficacy of the intervention. Study participants (English-speaking families with youth aged 5-14 years with insulin-dependent diabetes) were recruited from an urban hospital in Massachusetts, United States. In phase 1, parent-child pairs were invited to complete the intervention together and participate in 90-min user testing interviews assessing the tool's usability and acceptability. Interview transcripts were analyzed using a directed content analysis approach. In phase 2, parent-child pairs were invited to complete the intervention together in the clinical setting. Measures included parental and child knowledge, attitudes, and behaviors related to diabetes management (self-report surveys) and child hemoglobin A1c levels (medical record extractions); data were collected at baseline and 1-month follow-up. Pre- and postoutcomes were compared using paired $t$ tests and the Fisher exact test.

Results: A total of 11 parent-child pairs $(\mathrm{N}=22)$ participated in phase 1 of the study, and 10 parent-child pairs $(\mathrm{N}=20)$ participated in phase 2 of the study. Participants viewed the mobile educational tool as acceptable (high engagement and satisfaction with the layout, activities, and videos) and identified the areas of improvement for tool usability (duration, directions, and animation).

Conclusions: The findings from this pilot study suggest that the mobile educational tool is an informative, engaging, and feasible way to deliver diabetes self-management education to parents and children in an urban hospital setting. Data will inform future iterations of this mobile diabetes educational intervention to improve usability and test intervention efficacy.

(JMIR Form Res 2020;4(5):e16262) doi: 10.2196/16262

\section{KEYWORDS}

diabetes mellitus; self-management; health education; mHealth; mobile health; child health 


\section{Introduction}

\section{Background}

Type 1 diabetes (T1D) and type 2 diabetes (T2D) are among the most common chronic illnesses in children. Rates of T2D are disproportionately higher among American Indian, Hispanic, and black youth compared with white youth in the United States [1]. Pediatric diabetes adversely affects quality of life, productivity, and life expectancy and contributes to enormous health care costs, particularly given its increasing prevalence [2-5]. Earlier onset of diabetes also increases the risk and severity of diabetes-related complications [6,7]. Developing strategies to help youth and parents succeed in diabetes self-management is needed to promote positive health outcomes.

Extensive education is required to equip youth and families with the knowledge and skills needed to manage diabetes. Current diabetes management educational tools provided to families in the clinical setting are inadequate and text heavy, with parents often reporting that the educational process is overwhelming and lacks a patient-centered approach [8-10]. Furthermore, current diabetes self-management educational materials are not child centered (developed based on the needs and interests of children). As children transition into adolescence, the responsibility for diabetes management shifts from parents to the children [11]. Educational materials designed specifically for children, particularly those in preadolescence and early adolescence, are needed to facilitate the transition from parent-initiated diabetes management to self-management. To ease this transition, educational materials need to (1) engage youth and (2) facilitate positive, productive communication between parents and youth [12].

A growing number of studies have used mobile health to target diabetes self-management among adolescents [10,13-17]. The findings from such studies indicate the potential for mobile health interventions to enhance diabetes education, motivate behavior change, and have widespread dissemination. However, prior studies on mobile diabetes self-management interventions have focused primarily on adolescents (aged 12 to 19 years) [15-17]. The extent to which mobile diabetes self-management tools may be applicable for younger children and facilitate productive parent-child communication has not been extensively explored. In-depth research with parents' and children's perceptions and experiences with a child-centered, mobile diabetes educational intervention can inform the development and improvement of such tools.

\section{Objectives}

This pilot study aimed to (1) gather qualitative data on the usability and acceptability of the Mobile Diabetes Educator (MDE) prototype through user testing interviews with parent-child pairs (phase 1) and (2) assess the feasibility and preliminary efficacy of delivering the MDE in a clinical setting among parent-child pairs through a single-arm pre- and posttrial (phase 2). Phases were run concurrently with differing study participants using a mixed methods approach to achieve study aims. We hypothesized that trends in improvements in diabetes knowledge, attitudes, and self-management behaviors at 4- to 6-week follow-up would be observed.

\section{Methods}

\section{Mobile Diabetes Educator Intervention Prototype}

In collaboration with children's educational media consultants, the study team developed a prototype of the MDE [18]. This mobile educational program (interactive electronic book) was designed for school-aged youth and intended to be navigated by parents and children together to facilitate communication. The MDE prototype consists of eight animated, interactive modules that feature an ethnically ambiguous preadolescent character named Kara who has T1D (Figures 1 and 2). Topics covered include diabetes etiology, managing glucose levels, and diet and exercise recommendations. Multimedia strategies (eg, images and videos) were used for information delivery as they play a crucial role in learning. Images serve to improve perception, understanding, and memory and to encourage engagement by the user $[19,20]$. Using visuals is also an important mode of risk communication because the visual cortex of the brain becomes activated during high-stress situations [21,22].

The tool can be accessed through any mobile or computer device with internet access, although it was specifically designed for touchscreen navigation on a tablet. The interactive modules were designed to be completed in segments, self-directed at the patient's own pace, to replace text-based educational materials in the clinical setting after an initial diabetes diagnosis. For the purposes of this study, the modules were completed in one sitting (approximately 45-60 min). 
Figure 1. A page in the Mobile Diabetes Educator (MDE) that features interactive learning. This activity asks the patient to drag various steps needed for blood glucose monitoring into the correct order and check their results.

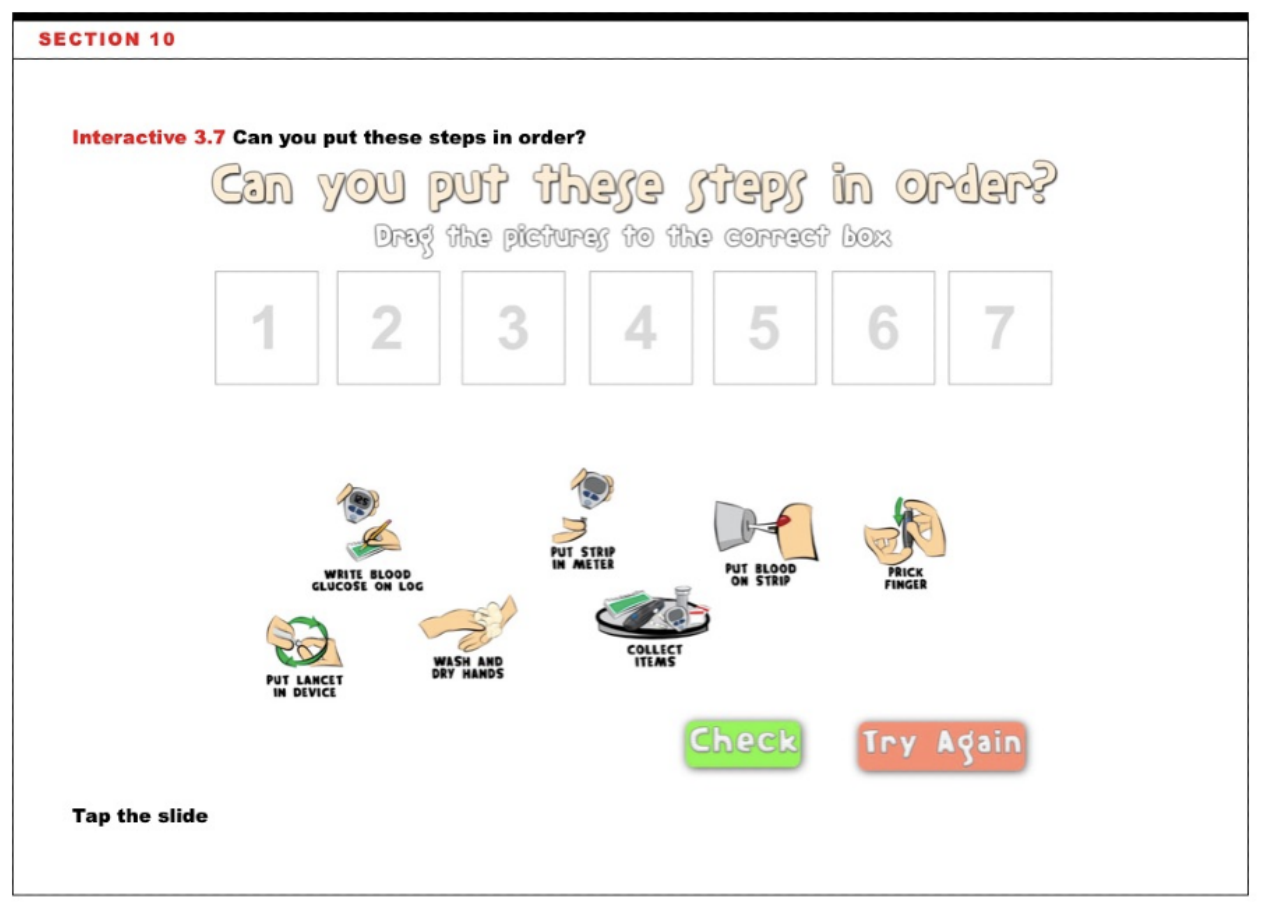

Figure 2. A page in the Mobile Diabetes Educator (MDE) that presents symptoms of hyperglycemia.

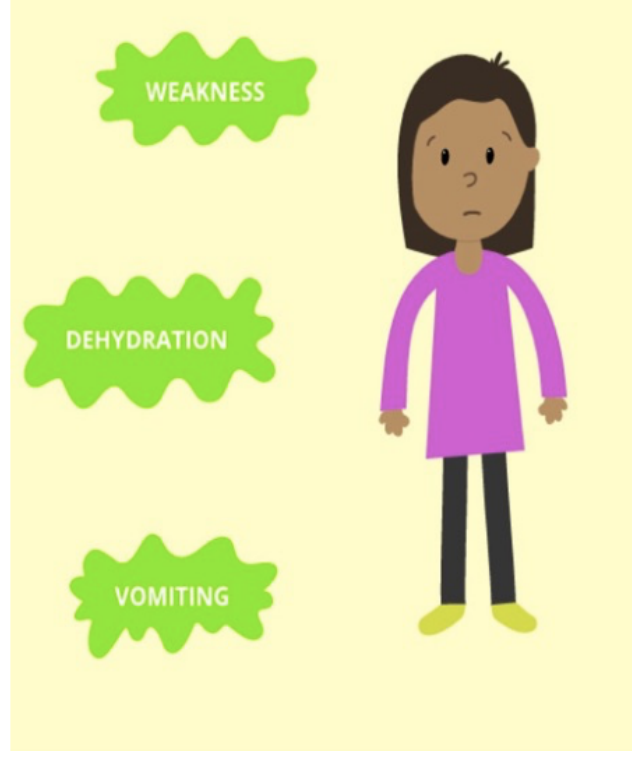

\section{Study Participants and Setting}

In both phases of the study, child participants and their parents or caregivers were recruited through the Pediatric Diabetes and Endocrinology Section at Boston Medical Center (BMC), a safety net urban hospital in Massachusetts, United States. A wide age range (elementary school-aged and middle school-aged youth) of child participants was used to examine the extent to which the tool was acceptable, engaging, and relevant across different age ranges. Eligibility criteria for child participants included (1) being aged 5 to 14 years, (2) being diagnosed by a clinician as insulin dependent (T1D or T2D), (3) currently receiving diabetes care at BMC, (4) parent consent

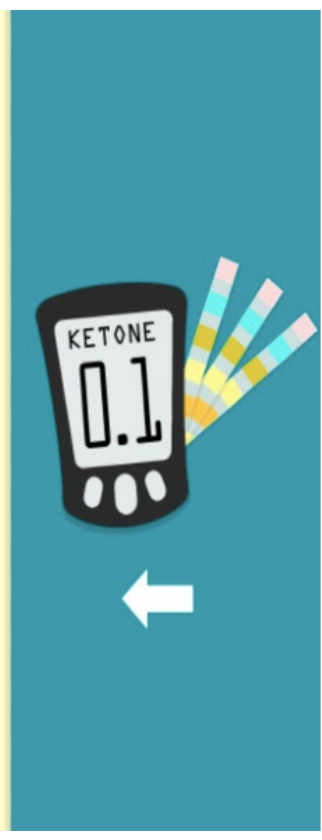

to participate, and (5) being able to read and converse in English. Eligibility criteria for parent participants included (1) being aged 18 years or older and (2) being able to read and converse in English. All study procedures took place in the BMC clinical setting.

\section{Phase 1: User Testing Interviews and Measures}

Phase 1 consisted of collecting qualitative data to assess usability and acceptability through user testing observations and interviews, an appropriate method given the low literacy level of our target population and the cognitive developmental stage of some of our child participants (eg, children aged 5-7 years may not understand how to answer standardized measures of 
usability, whereas study team observations and open-ended questions may generate more insights). User testing lasted approximately $90 \mathrm{~min}$ and consisted of an observational component and a semistructured interview. The study team provided participants with a tablet with the intervention preloaded and asked participants to use the tool and explain their thinking out loud as they navigated the tool. Study staff silently observed how participants navigated the tool and noted areas for improvement in usability (ease of navigation and problems encountered, time taken to complete the tool, and identification of the primary user [parent, child, or equal use between parents and children]) and acceptability (frequency, content, and tone of parent-child communication for pair users and level of participant engagement). Immediately after completing the tool, study staff conducted semistructured interviews and asked participants to evaluate the tool in terms of additional acceptability measures (clarity of content, acceptability of contexts [eg, characters and settings], perceived purpose of the tool, overall satisfaction, and areas for improvement; see Multimedia Appendix 1).

\section{Phase 1: Qualitative Analysis}

Interviews were audio recorded, transcribed verbatim, and thematically analyzed by study staff. The analysis used a directed content analysis approach [23]. An initial codebook was developed based on the interview guide. Following transcript coding by study staff, codes were revised to incorporate additional themes as needed. Thus, both a priori and de novo themes were identified and given an operational definition. Coders also identified quotes that represented each theme.

\section{Phase 2: Feasibility Trial and Measures}

Phase 2 consisted of collecting quantitative data to assess preliminary efficacy using self-reported surveys and medical record information. Parent and child participants completed a baseline assessment immediately before participating in a 1-hour intervention session and a postassessment 4 to 6 weeks later (all completed in the clinical setting). For the intervention session, parent-child pairs were provided with a tablet and asked to complete the intervention (self-administered) together. The following four measures on diabetes: knowledge, self-efficacy, self-management, and communication were each completed separately by both child and parent participants using self-report, self-administered surveys. Diabetes knowledge was assessed using 25 multiple-choice items from the Revised Brief Diabetes Knowledge Test [24], with the percentage of correctly answered items calculated. Sample diabetes knowledge topics covered included nutrition, glucose testing, glucose reactions, and insulin. Sample questions included (1) A low blood glucose reaction may be caused by too much insulin, too little insulin, too much food, or too little exercise and (2) Which of the following is highest in carbohydrates? Baked chicken, swiss cheese, baked potato, or peanut butter. Diabetes management self-efficacy was measured using 19 items from the Diabetes Self-Efficacy Scale [25], which asked respondents to rate their confidence in their ability to manage diabetes (eg, glucose self-monitoring, insulin injections, and meal planning) using a 5-point Likert scale, ranging from 1 (very sure I cannot) to 5 (very sure I can). Perceived readiness for diabetes self-management was measured using two items from the Readiness to Change the Balance of Responsibility Scale [26]. These items included "I feel ready to manage diabetes on my own" and "I feel ready to take on some, but not all, of diabetes management on my own," which were assessed using a 5-point Likert scale, ranging from 1 (very sure I cannot) to 5 (very sure I can). The frequency of parent-child diabetes management communication was assessed using three items from the Self-Management of T1D in Adolescence subscale [27]. Participants were asked to report how often they talk to their parents about diabetes, when they have questions about diabetes, and when they have problems managing diabetes using a 4-point frequency scale (always, sometimes, occasionally, and never). Child sociodemographics included gender, age, race and ethnicity, and type of insulin-dependent diabetes diagnosis (T1D or T2D). Child hemoglobin $\mathrm{A}_{1 \mathrm{c}}\left(\mathrm{HbA}_{1 \mathrm{c}}\right)$ levels were extracted from child participants' medical records by a trained patient navigator. Parental sociodemographics included gender, age, race and ethnicity, annual household income, highest level of education completed, and occupational status (employed full time, employed part time, or other).

\section{Phase 2: Statistical Analysis}

Distributions, descriptive statistics, and missing values were examined for all measures. Changes in parent and child outcomes from pre- and postassessments were analyzed using paired $t$ tests for continuous outcomes and the Fisher exact test for categorical outcomes. Statistical analyses were conducted using SAS version 9.4. The data were considered to be statistically significant at an alpha value of .05 .

\section{Results}

\section{Sociodemographics}

The phase 1 study sample consisted of 11 parent-child pairs $(\mathrm{N}=22)$. Among child participants, the mean age was 10.3 (SD 2.2) years, and nearly two-thirds $(7 / 11,64 \%)$ of them were female. Almost all $(10 / 11,91 \%)$ participants had T1D. Among parents, the mean age was 39.5 (SD 11.0) years. The majority of parent participants were female $(10 / 11,91 \%)$, had less than a college degree $(10 / 11,91 \%)$, and had an annual household income less than US $\$ 50,000(9 / 11,82 \%)$. See Table 1 for additional sociodemographics on phase 1 participants. 
Table 1. Baseline characteristics of the parent-child pairs participating in phase 1 and phase 2 of the Mobile Diabetes Educator pilot study (2018-2019).

\begin{tabular}{|c|c|c|}
\hline Baseline characteristics & Phase $1(\mathrm{~N}=11)$ & Phase $2(\mathrm{~N}=10)$ \\
\hline \multicolumn{3}{|l|}{ Child } \\
\hline \multicolumn{3}{|l|}{ Gender, n (\%) } \\
\hline Female & $7(64)$ & $5(50)$ \\
\hline Male & $4(36)$ & $5(50)$ \\
\hline Age (years), mean (SD) & $10.3(2.2)$ & $10.8(2.9)$ \\
\hline \multicolumn{3}{|l|}{ Race, $\mathbf{n}(\%)$} \\
\hline White & $1(9)$ & $1(10)$ \\
\hline Black & $6(55)$ & $5(50)$ \\
\hline Hispanic or Latino & $1(9)$ & $1(10)$ \\
\hline Other & $3(27)$ & $3(30)$ \\
\hline \multicolumn{3}{|l|}{ Type of insulin-dependent diabetes, $n(\%)$} \\
\hline Type 1 & $10(91)$ & $9(90)$ \\
\hline Type 2 & $1(9)$ & $1(10)$ \\
\hline \multicolumn{3}{|l|}{ Parent } \\
\hline \multicolumn{3}{|l|}{ Gender, n (\%) } \\
\hline Female & $10(91)$ & $8(80)$ \\
\hline Male & $1(9)$ & $2(20)$ \\
\hline Age (years), mean (SD) & $39.5(11.0)$ & $40.8(11.2)$ \\
\hline \multicolumn{3}{|l|}{ Race, $n(\%)$} \\
\hline White & $2(18)$ & $3(30)$ \\
\hline Black & $8(73)$ & $6(60)$ \\
\hline Hispanic or Latino & $1(9)$ & $1(10)$ \\
\hline Other & $0(0)$ & $0(0)$ \\
\hline \multicolumn{3}{|l|}{ Annual household income, n (\%) } \\
\hline Less than US $\$ 30,000$ & $4(36)$ & $5(50)$ \\
\hline US $\$ 30,000-\$ 49,999$ & $5(45)$ & $3(30)$ \\
\hline Greater than or equal to US $\$ 50,000$ & $2(18)$ & $2(20)$ \\
\hline \multicolumn{3}{|l|}{ Education, n (\%) } \\
\hline Less than or equal to high school degree & $6(55)$ & $6(60)$ \\
\hline Some college & $4(36)$ & $3(30)$ \\
\hline Greater than or equal to college degree & $1(9)$ & $1(10)$ \\
\hline \multicolumn{3}{|l|}{ Occupation, $\mathrm{n}(\%)$} \\
\hline Employed full time & $6(55)$ & $4(40)$ \\
\hline Employed part time & $2(18)$ & $2(20)$ \\
\hline Other (disabled, retired, unemployed, or homemaker) & $3(27)$ & $4(40)$ \\
\hline
\end{tabular}

The phase 2 study sample consisted of 10 parent-child pairs $(\mathrm{N}=20)$. Among children, the mean age was 10.8 (SD 2.9) years, and half $(5 / 10,50 \%)$ of them were female. Almost all $(9 / 10$, $90 \%$ ) participants had T1D. Among parents, the mean age was 40.8 (SD 11.2) years. The majority of parent participants were female $(8 / 10,80 \%)$, had less than a college degree $(9 / 10,90 \%)$, and had an annual household income less than US $\$ 50,000$ $(8 / 10,80 \%)$. See Table 1 for additional sociodemographics on phase 2 participants.

\section{Phase 1: User Testing Observations}

Study staff's observations of parent-child interactions during user testing provided insight into the usability and acceptability of the MDE tool (Table 2). The majority $(6 / 11,55 \%)$ of parent-child pairs demonstrated shared use of the tool (ie, taking turns holding the tool, reading content, and completing activities), although in some $(4 / 11,36 \%)$ instances, the child was the primary user. Although most $(9 / 11,82 \%)$ users 
encountered problems using the tool, the overall navigation of the tool appeared either easy $(5 / 11,46 \%)$ or moderately easy $(4 / 11,36 \%)$ according to study staff's observations. Parental and child engagement with the tool was distributed by engagement level. Observers noted that $55 \%(6 / 11)$ of parents and $36 \%(4 / 11)$ of children were highly engaged, whereas $27 \%$ $(3 / 11)$ of parents and $36 \%$ (4/11) of children demonstrated a moderate level of engagement. Observers also noticed high $(5 / 11,46 \%)$ and moderate $(3 / 11,27 \%)$ parent-child communication during user testing.

Table 2. User testing observations of 11 parent-child pairs participating in phase 1 of the Mobile Diabetes Educator pilot study (2018-2019).

\begin{tabular}{|c|c|}
\hline Staff-rated observations & Values, n (\%) \\
\hline \multicolumn{2}{|l|}{ Ease of navigation } \\
\hline Easy & $5(45)$ \\
\hline Moderate & $4(36)$ \\
\hline Difficult & $2(18)$ \\
\hline \multicolumn{2}{|c|}{ User problems encountered } \\
\hline Yes & $9(82)$ \\
\hline No & $2(18)$ \\
\hline \multicolumn{2}{|l|}{ Primary user } \\
\hline Parent & $1(9)$ \\
\hline Child & $4(36)$ \\
\hline Equal use & $6(55)$ \\
\hline \multicolumn{2}{|l|}{ Parent engagement } \\
\hline High & $6(55)$ \\
\hline Moderate & $3(27)$ \\
\hline Low & $2(18)$ \\
\hline \multicolumn{2}{|l|}{ Child engagement } \\
\hline High & $4(36)$ \\
\hline Moderate & $4(36)$ \\
\hline Low & $3(27)$ \\
\hline \multicolumn{2}{|c|}{ Parent-child communication } \\
\hline High & $5(45)$ \\
\hline Moderate & $3(27)$ \\
\hline Low & $3(27)$ \\
\hline
\end{tabular}

\section{Phase 1: User Testing Interviews}

Thematic analysis of semistructured interviews with parent-child pairs further explored the usability and acceptability of the MDE tool. In total, seven themes were identified and coded based on the semistructured interview guide: usability, comprehension, high engagement, low engagement, purpose, satisfaction, and suggestions for improvement. These themes, alongside illustrative quotes, are summarized in Table 3 and discussed below. 
Table 3. Illustrative quotes by theme from user testing interviews with 11 parent-child pairs participating in phase 1 of the Mobile Diabetes Educator pilot study (2018-2019).

\begin{tabular}{ll}
\hline Theme & Illustrative quotes \\
\hline Usability & $\begin{array}{l}\text { Somewhat user friendly } \\
\text { "I think certain areas were just a little confusing so you couldn't really tell whether or not you're supposed to tap } \\
\text { on it or are you just supposed to go to the next screen." }\end{array}$ \\
$\begin{array}{l}\text { Comprehension } \\
\text { High comprehension }\end{array}$ & $\begin{array}{l}\text { "It got to the point. It explained the situations and what to look for in the situations. It explained it a lot. A kid would } \\
\text { understand it." }\end{array}$ \\
High engagement & "I liked that it alternated with videos and then text." \\
Layout & $\begin{array}{l}\text { "I think they are helpful in the sense that they kind of test your knowledge and help you to get a better understanding } \\
\text { of itivities }\end{array}$ \\
"My favorite part was basically explaining why people have diabetes." \\
"I liked the animated videos. I think that keeps you going. Looking at the lady sitting there just talking [whereas] \\
looking at the animation, they're doing things so it makes you want to look at it more."
\end{tabular}

\title{
Low engagement
}

Activities

Chapters

Characters

Purpose

Health education

Health management

Motivation for diabetes self-management

\author{
"Some of them were confusing and some of them were boring. And then some of them were just 'meh."' \\ "Too many chapters." \\ "I just thought it was weird they had no arms and legs."
}

\section{Satisfaction}

Moderate satisfaction

$$
\begin{aligned}
& \text { "To educate kids about diabetes in a fun way. To let them know it's ok to have diabetes. This stuff happens in normal } \\
& \text { life, it happens in school. It tells them what to do also, but in a fun way." } \\
& \text { "Learning about it and how to maintain it, and keep yourself healthy." } \\
& \text { "To tell us that it is not easy to take care of [diabetes] but you have to try your best and eat more healthy food so } \\
& \text { you won't get sick." }
\end{aligned}
$$

"I say 7 [out of 10] because like I said from earlier, just those little kinks that need to be worked out. But outside of that, I think it's a really good tool to educate and inform others about diabetes, especially for a child that is new to it and kind of clueless and going through it. So, it's a good way to help them to understand it on their level."

\section{Suggestions for improvement}

Usability

Comprehension
Layout
Chapters
Activities
Characters
Settings

"A little more instruction at the top of the screen on what's expected on that particular screen, that slide."

"I would only suggest doing the content a little bit more on the kids' level-especially for younger kids-so they could really grasp the content just a little bit more. [For example], with the video with the nutrition, just doing all the way around on an animated level for kids if they're going to be the ones engaging on the iPad. But if it's more like older kids or adults, then yeah keep it the way it is."

"A little more videos and quizzes."

"I think they should have added more about the carbs. They should have at least given more clarification on how you would...how much insulin and how many carbs...they should have put that together more."

"Drawing. Maybe have the kids draw their idea of the pancreas and all that stuff."

"I think she should sound more like a kid. I think all of them should."

"More settings would be nice. Especially when we're taking trips out and then to know what you need or how to do things when you're in a car. Stuff like that."

\section{Usability}

Most participants described the tool as somewhat user friendly. Any difficulty using the tool was attributed to two main reasons: a lack of directions and malfunctioning activities. Given that there is a mix of text, videos, and activities throughout the tool, users felt unclear at times of what they were supposed to do on any given slide (eg, whether it was an interactive slide or not and what to press to engage in activity). Users also expressed frustration with some activities that did not work (eg, press button and nothing happens). However, in some cases, what appeared to be a malfunction was just difficulty navigating the activity because of a lack of directions (eg, unclear that the user must select icons sequentially for an activity to work). 


\section{Comprehension}

Participants found the tool to be informative and thought the material was easy to understand, signifying an appropriate literacy level. Both parent and child users could demonstrate that they learned diabetes-related information after completing the tool. Notably, the visuals used throughout the tool (eg, pictorial representation of symptoms) helped increase comprehension of the information being conveyed.

\section{High Engagement}

As participants discussed parts of the tool they liked the most, several subthemes emerged, including layout, chapters, activities, and videos. The overall layout of the tool, which included a mix of text, videos, and activities, provided both passive and active learning opportunities for users, thereby increasing their engagement with the tool (eg, was able to hold children's attention by giving them things to do). Participants largely felt that the chapters covered all the basic topics. The chapters on diabetes etiology and celebrities with diabetes were particularly engaging for children, whereas the chapters that demonstrated diabetes management and care (eg, insulin injection) were of interest to parents. The activities were often cited as the most engaging aspect of the tool and a positive way to reinforce the knowledge learned. Participants also enjoyed the videos, as they made the information easier to understand (eg, animated cells and organs were helpful in understanding diabetes etiology). Although participants liked the balance of animated and nonanimated videos, some cited the animations as slightly more engaging, especially for children.

\section{Low Engagement}

As participants discussed parts of the tool they found less interesting, the following subthemes emerged: duration, characters, and setting. The average time it took for users to complete the tool was 56 min (SD 15), which many felt was too long and contributed to a general feeling of boredom. Although participants typically liked the main character and her personality, they repeatedly expressed dissatisfaction with the robotic voice and appearance (eg, missing arms and legs) of the animated characters. Similarly, although the school-based settings of the animated videos felt true to life, participants would have liked to see more settings, particularly when children are on the go (eg, in the car) or without their parents (eg, birthday party and sleepover).

\section{Purpose}

Most participants thought the main purpose of the tool was to provide health education (eg, target knowledge). Participants described the target audience for this tool as newly diagnosed patients or people who do not already know about diabetes.
Other main purpose subthemes that emerged included health management (eg, target behaviors) and motivation for diabetes self-management (eg, target attitudes).

\section{Satisfaction}

The majority of participants reported high satisfaction with the tool. On a scale of 1 to 10 , with 10 being the best, participants' average rating was 8.7 (SD 1.5). High satisfaction was often attributed to the fact that the tool was entertaining and provided a great deal of information. Factors that lowered users' satisfaction scores included the long duration and, thus, boringness of the tool as well as the aforementioned usability issues with some activities.

\section{Suggestions for Improvement}

Participants suggested several ways to improve the tool in relation to the following subthemes: usability, comprehension, layout, activities, characters, duration, and dissemination. To improve the tool's usability, clear directions should be included on each slide, and malfunctioning activities should be fixed. Comprehension could be enhanced by increasing the use of child-friendly explanations of information (eg, pictures to complement or replace words and more animation). Similarly, participants thought more engaging, creative features, such as videos and activities, should be added to enrich the overall layout of the tool. Suggestions for new activities included a word search, summary quiz, drawing, or having the user watch a video on how to perform a behavior and then practice doing so on a cartoon. According to participants, animated characters should have a less robotic voice and more realistic appearance. The use of superhero characters was also suggested. Finally, participants agreed that the duration of the tool should be shortened, yet they found it difficult to identify ways to do so (eg, information that could be cut). However, disseminating the $\mathrm{MDE}$ as an app was recommended to allow users to cover the material at their own pace at home.

\section{Phase 2: Outcomes}

Participants spent an average of 59.2 (SD 5.4) min to complete the intervention in one sitting. The retention rate for follow-up assessments was $80 \%(8 / 10)$. No significant changes in child participants' diabetes self-management knowledge test scores, self-efficacy, parental communication, or $\mathrm{HbA}_{1 \mathrm{c}}$ levels were observed at 4- to 6-week follow-up (Table 4). Among parent participants, no significant changes were observed for the diabetes knowledge, attitudes, and behavioral measures. Although not statistically significant, we did find trends toward increasing knowledge and decreasing self-efficacy for diabetes management among both children and parents. 
Table 4. Pre- and postchanges in knowledge, attitudes, and behaviors of 10 parent-child pairs participating in phase 2 of the Mobile Diabetes Educator pilot study (2018-2019).

\begin{tabular}{|c|c|c|c|}
\hline Outcome & Pretest $(\mathrm{N}=10)$ & Posttest $(\mathrm{N}=8)$ & $P$ value $^{\mathrm{a}}$ \\
\hline \multicolumn{4}{|l|}{ Child } \\
\hline Diabetes Knowledge Test score (percentage correct) ${ }^{\mathrm{b}}$, mean (SD) & $51.6(21.8)$ & $65.0(9.5)$ & .08 \\
\hline Child self-efficacy in diabetes self-management score ${ }^{\mathrm{b}}$, mean (SD) & $59.9(11.6)$ & $55.3(17.6)$ & .51 \\
\hline $\begin{array}{l}\text { Children who report "always" talking with their parents when they have problems managing their } \\
\text { diabetes }^{\mathrm{c}}, \mathrm{n}(\%)\end{array}$ & $6(60)$ & $5(63)$ & .35 \\
\hline $\begin{array}{l}\text { Children who report a score of } 4 \text { or a } 5 \text { for believing they can manage diabetes by themselves (high } \\
\text { confidence) }{ }^{\mathrm{c}}, \mathrm{n}(\%)\end{array}$ & $2(20)$ & $3(38)$ & .36 \\
\hline Hemoglobin $\mathrm{A}_{1 \mathrm{c}}$ levels ${ }^{\mathrm{b}}$, mean (SD) & $9.6(1.6)$ & $9.9(1.5)$ & .71 \\
\hline \multicolumn{4}{|l|}{ Parent } \\
\hline Diabetes Knowledge Test score (percentage correct) ${ }^{\mathrm{b}}$, mean (SD) & $60.0(14.9)$ & $70.8(13.9)$ & .12 \\
\hline Parental self-efficacy in helping their child manage diabetes score ${ }^{\mathrm{b}}$, mean (SD) & $78.5(6.2)$ & $70.5(22.1)$ & .29 \\
\hline $\begin{array}{l}\text { Parents who report that their child "always" tells them when he or she is having problems managing } \\
\text { diabetes }{ }^{\mathrm{c}}, \mathrm{n}(\%)\end{array}$ & $8(80)$ & $4(50)$ & .50 \\
\hline $\begin{array}{l}\text { Parents who report a score of } 4 \text { or a } 5 \text { for believing that their child can manage diabetes on his or her } \\
\text { own (high confidence) }{ }^{\mathrm{c}}, \mathrm{n}(\%)\end{array}$ & $4(40)$ & $3(38)$ & .66 \\
\hline Average number of times their child had a blood glucose checked in the last 24 hours ${ }^{\mathrm{b},}$ mean (SD) & $4.4(2.0)$ & $3.6(2.1)$ & .05 \\
\hline
\end{tabular}

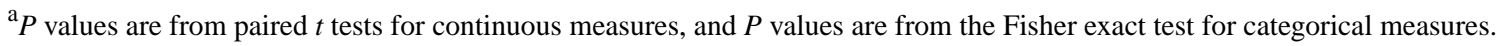

${ }^{\mathrm{b}}$ Continuous measure.

${ }^{\mathrm{c}}$ Categorical measure.

\section{Discussion}

\section{Principal Findings}

This pilot study demonstrated that the MDE was an acceptable and appropriate mobile health intervention for insulin-dependent children and their parents in a clinical setting. Participants were particularly satisfied with the overall layout of the tool (ie, mix of text, videos, and activities) and the information conveyed. The activities were often cited as the most engaging aspect of the tool and a positive way to reinforce the knowledge learned. Although the MDE was well received by participants, qualitative data indicated a need for improvements to the usability of the tool. Specifically, participants suggested adding directions to each slide and fixing malfunctioning activities. Participants also expressed a strong desire for a shorter duration.

Overall, no significant differences were observed between baseline and follow-up assessments among child and parent participants' knowledge, attitudes, behaviors, and outcomes related to diabetes self-management. Given that this was a small feasibility study that was not powered to detect changes in outcomes, null findings were expected. With respect to our clinical outcome (child $\mathrm{HbA}_{1 \mathrm{c}}$ levels), null findings may also be because of the short follow-up period and the nature of the intervention. There is mixed evidence of educational and mobile-based interventions and their ability to affect $\mathrm{HbA}_{1 \mathrm{c}}$ in pediatric diabetes populations $[8,10,28]$, especially during adolescence when glycemic control typically worsens [29]. Although not statistically significant, slight decreases in parental self-efficacy and the percentage of parents who perceived that their child could manage diabetes on their own were observed. One potential explanation for this finding is that the MDE highlighted gaps of knowledge and understanding of how to manage diabetes among parents, and the finding suggests that such tools may be used to help identify and target the lack of understanding or misperceptions of diabetes management among children and parents. We also observed a notable, although statistically insignificant, decrease in the percentage of parents who reported that their child always tells them when they are having problems managing diabetes. This trend could be the result of parent-child communication facilitated by the MDE about diabetes self-management that helped identify gaps in the child's ability to manage diabetes.

\section{Lessons Learned}

The findings from this mixed methods pilot study provide useful insight into the usability and acceptability of the MDE. Key recommendations regarding usability focused on directions and malfunctioning activities, whereas recommendations to improve acceptability focused on duration and animated characters. In regard to intervention delivery, we learned that youth with diabetes and their parents would also be interested in using this tool outside of the clinical setting (eg, at home via app). These lessons learned will be used to shape the next prototype of the MDE. A responsive website design, ideal for the burgeoning predominance of mobile Web browsing, could be included in the next iterative developmental stage along with translation to 
Spanish to further extend the target of this diabetes intervention tool to another high-risk underrepresented patient population.

\section{Comparison With Prior Work}

Prior research demonstrates that mobile health interventions can be used to target knowledge, self-efficacy, and self-management behavior among patients with diabetes [30-32]. Characteristics of prior mobile health interventions for diabetes include access to educational information (eg, text pages, videos, and Web-based simulation), health information storage (eg, blood glucose readings and medication tracking), social networking (eg, storyboard, blog, and discussion board), and communication (eg, with health professionals, among parents and children) $[12,15,30,31,33]$. One key feature of our tool was the activities that engaged children in diabetes education (Figure 1).

Suggestions to improve mobile educational tools from our study are consistent with research on educational mobile tools for the self-management of other chronic diseases among youth. For example, adolescents with asthma suggested that informative videos covering asthma topics (eg, visual demonstration of inhaler technique) and quizzes be included in an asthma self-management app [34], two specific suggestions that were also voiced by participants in our user testing interviews. To date, mobile health intervention studies for patients with diabetes have largely focused on adolescents [10,14-17,31,32]. Our pilot study targeted a younger age range (5-14 years) as well as parents to explore the feasibility and acceptability of a mobile educational intervention among parent-child pairs. Additional content may need to be tailored for this younger population, such as school accommodations and communication, special events (eg, parties and camp), strategies for injection, and instructions about foods. Our sample also consisted of youth from low-income and racial minority populations, who experience disproportionately higher rates of T2D and diabetes-related adverse events $[35,36]$ and are inadequately represented in diabetes intervention research. These sample characteristics are significant, given that the data gathered from this pilot study (eg, user testing feedback) will be used to further develop the MDE prototype, better ensuring that the needs and preferences of affected populations are reflected in the design of interventions.

\section{Strengths and Limitations}

Strengths of this study include the in-depth qualitative methods used to examine intervention usability, acceptability, and feasibility and the recruitment of underserved study participants from an urban hospital setting to inform intervention refinement and study procedures for a larger trial. Limitations of this study include the small sample size, the absence of a control group for comparisons, a short follow-up period, and limited generalizability. Although it was a strength that our sample consisted of ethnically diverse, primarily low-income families, this limited our ability to control for race and ethnicity and income.

\section{Conclusions}

Given the ubiquity of mobile devices, a child-centered mobile health intervention that engages children and parents has the potential to enhance pediatric diabetes management. The findings from this pilot study will be used to inform the next iteration of the MDE tool so that the user testing feedback can be incorporated and the intervention efficacy can be tested on a larger scale.

\section{Acknowledgments}

This research was supported by the Boston University School of Public Health Early Career Catalyst Award. The authors would like to acknowledge staff and study participants at BMC for their support, guidance, and participation in study activities.

\section{Conflicts of Interest}

None declared.

\section{Multimedia Appendix 1}

Semistructured interview guide. [DOCX File, 15 KB-Multimedia Appendix 1]

\section{References}

1. Dabelea D, Mayer-Davis EJ, Saydah S, Imperatore G, Linder B, Divers J, SEARCH for Diabetes in Youth Study. Prevalence of type 1 and type 2 diabetes among children and adolescents from 2001 to 2009. J Am Med Assoc 2014 May 7;311(17):1778-1786 [FREE Full text] [doi: 10.1001/jama.2014.3201] [Medline: 24794371]

2. SEARCH for Diabetes in Youth Study Group, Liese AD, D'Agostino RB, Hamman RF, Kilgo PD, Lawrence JM, et al. The burden of diabetes mellitus among US youth: prevalence estimates from the SEARCH for Diabetes in Youth Study. Pediatrics 2006 Oct;118(4):1510-1518. [doi: 10.1542/peds.2006-0690] [Medline: 17015542]

3. Hamman RF, Bell RA, Dabelea D, D'Agostino RB, Dolan L, Imperatore G, SEARCH for Diabetes in Youth Study Group. The SEARCH for Diabetes in Youth study: rationale, findings, and future directions. Diabetes Care 2014 Dec;37(12):3336-3344 [FREE Full text] [doi: 10.2337/dc14-0574] [Medline: 25414389]

4. Gale EA. The rise of childhood type 1 diabetes in the 20th century. Diabetes 2002 Dec;51(12):3353-3361 [FREE Full text] [doi: 10.2337/diabetes.51.12.3353] [Medline: 12453886] 
5. Aanstoot HJ, Anderson BJ, Daneman D, Danne T, Donaghue K, Kaufman F, et al. The global burden of youth diabetes: perspectives and potential. Pediatr Diabetes 2007 Oct;8(Suppl 8):1-44. [doi: 10.1111/j.1399-5448.2007.00326.x] [Medline: $\underline{17767619]}$

6. Imperatore G, Boyle JP, Thompson TJ, Case D, Dabelea D, Hamman RF, SEARCH for Diabetes in Youth Study Group. Projections of type 1 and type 2 diabetes burden in the US population aged <20 years through 2050: dynamic modeling of incidence, mortality, and population growth. Diabetes Care 2012 Dec;35(12):2515-2520 [FREE Full text] [doi: 10.2337/dc12-0669] [Medline: 23173134]

7. Naranjo D, Schwartz DD, Delamater AM. Diabetes in ethnically diverse youth: disparate burden and intervention approaches. Curr Diabetes Rev 2015;11(4):251-260. [doi: 10.2174/1573399811666150421115846] [Medline: 25901501]

8. Hampson SE, Skinner TC, Hart J, Storey L, Gage H, Foxcroft D, et al. Effects of educational and psychosocial interventions for adolescents with diabetes mellitus: a systematic review. Health Technol Assess 2001;5(10):1-79 [FREE Full text] [doi: 10.3310/hta5100] [Medline: 11319990$]$

9. Jönsson L, Hallström I, Lundqvist A. 'The logic of care' - parents' perceptions of the educational process when a child is newly diagnosed with type 1 diabetes. BMC Pediatr 2012 Oct 20;12:165 [FREE Full text] [doi: 10.1186/1471-2431-12-165] [Medline: 23083125]

10. Deacon AJ, Edirippulige S. Using mobile technology to motivate adolescents with type 1 diabetes mellitus: a systematic review of recent literature. J Telemed Telecare 2015 Dec;21(8):431-438. [doi: 10.1177/1357633X15605223] [Medline: 26377124]

11. Ersig AL, Tsalikian E, Coffey J, Williams JK. Stressors in teens with type 1 diabetes and their parents: immediate and long-term implications for transition to self-management. J Pediatr Nurs 2016;31(4):390-396. [doi: 10.1016/j.pedn.2015.12.012] [Medline: 26831378]

12. Hanberger L, Ludvigsson J, Nordfeldt S. Use of a web 2.0 portal to improve education and communication in young patients with families: randomized controlled trial. J Med Internet Res 2013 Aug 23;15(8):e175 [FREE Full text] [doi: 10.2196/jmir.2425] [Medline: 23973555]

13. Hilliard ME, Powell PW, Anderson BJ. Evidence-based behavioral interventions to promote diabetes management in children, adolescents, and families. Am Psychol 2016 Oct; 71(7):590-601 [FREE Full text] [doi: 10.1037/a0040359] [Medline: 27690487]

14. St George SM, Delamater AM, Pulgaron ER, Daigre A, Sanchez J. Access to and interest in using smartphone technology for the management of type 1 diabetes in ethnic minority adolescents and their parents. Diabetes Technol Ther 2016 Feb;18(2):104-109. [doi: 10.1089/dia.2015.0086] [Medline: 26840496]

15. Holtz BE, Murray KM, Hershey DD, Dunneback JK, Cotten SR, Holmstrom AJ, et al. Developing a patient-centered mHealth app: a tool for adolescents with type 1 diabetes and their parents. JMIR Mhealth Uhealth 2017 Apr 19;5(4):e53 [FREE Full text] [doi: 10.2196/mhealth.6654] [Medline: 28428167]

16. Majeed-Ariss R, Baildam E, Campbell M, Chieng A, Fallon D, Hall A, et al. Apps and adolescents: a systematic review of adolescents' use of mobile phone and tablet apps that support personal management of their chronic or long-term physical conditions. J Med Internet Res 2015 Dec 23;17(12):e287 [FREE Full text] [doi: 10.2196/jmir.5043] [Medline: 26701961]

17. Goyal S, Nunn CA, Rotondi M, Couperthwaite AB, Reiser S, Simone A, et al. A mobile app for the self-management of type 1 diabetes among adolescents: a randomized controlled trial. JMIR Mhealth Uhealth 2017 Jun 19;5(6):e82 [FREE Full text] [doi: 10.2196/mhealth.7336] [Medline: 28630037]

18. Bernier A, Fedele D, Guo Y, Chavez S, Smith MD, Warnick J, et al. New-onset diabetes educator to educate children and their caregivers about diabetes at the time of diagnosis: usability study. JMIR Diabetes 2018 Jun 6;3(2):e10 [FREE Full text] [doi: 10.2196/diabetes.9202] [Medline: 30291069]

19. Arizpe E, Styles M. Children Reading Pictures: Interpreting Visual Texts. First Edition. London: Routledge; 2002.

20. Carney R, Levin JR. Pictorial illustrations still improve students' learning from text. Educ Psychol Rev 2002;14(1):5-26. [doi: 10.1023/A:1013176309260]

21. Covello VT. Risk communication, radiation, and radiological emergencies: strategies, tools, and techniques. Health Phys 2011 Nov;101(5):511-530. [doi: 10.1097/HP.0b013e3182299549] [Medline: 21979532]

22. Covello V. Understanding \& communicating risk. In: Proceedings of the North American Menopause Society 23rd Annual Meeting. 2012 Oct 03 Presented at: The North American Menopause Society 23rd Annual Meeting; 2012; Orlando, Florida URL: https://www.healio.com/endocrinology/practice-management/news/print/endocrine-today/\% $7 \mathrm{Bf} 148 \mathrm{caf} 9-\mathrm{b} 4 \mathrm{f} 4-$ 4a3c-9d76-11ea0befe043\%7D/expert-shares-innovative-lessons-in-communicating-risk

23. Hsieh HF, Shannon SE. Three approaches to qualitative content analysis. Qual Health Res 2005 Nov;15(9):1277-1288. [doi: 10.1177/1049732305276687] [Medline: $\underline{16204405]}$

24. Fitzgerald JT, Funnell MM, Anderson RM, Nwankwo R, Stansfield RB, Piatt GA. Validation of the revised brief Diabetes Knowledge Test (DKT2). Diabetes Educ 2016 Apr;42(2):178-187. [doi: 10.1177/0145721715624968] [Medline: 26769757]

25. Rasbach L, Jenkins C, Laffel L. An integrative review of self-efficacy measurement instruments in youth with type 1 diabetes. Diabetes Educ 2015 Feb;41(1):43-58 [FREE Full text] [doi: 10.1177/0145721714550254] [Medline: 25216655] 
26. Kaugars AS, Kichler JC, Alemzadeh R. Assessing readiness to change the balance of responsibility for managing type 1 diabetes mellitus: adolescent, mother, and father perspectives. Pediatr Diabetes 2011 Sep;12(6):547-555. [doi: 10.1111/j.1399-5448.2010.00737.x] [Medline: 21446924]

27. Schilling LS, Dixon JK, Knafl KA, Lynn MR, Murphy K, Dumser S, et al. A new self-report measure of self-management of type 1 diabetes for adolescents. Nurs Res 2009;58(4):228-236 [FREE Full text] [doi: 10.1097/NNR.0b013e3181ac142a] [Medline: 19561555]

28. Peterson A. Improving type 1 diabetes management with mobile tools: a systematic review. J Diabetes Sci Technol 2014 Jul;8(4):859-864 [FREE Full text] [doi: 10.1177/1932296814529885] [Medline: 24876414]

29. Grey M, Whittemore R, Jeon S, Murphy K, Faulkner MS, Delamater A, TeenCope Study Group. Internet psycho-education programs improve outcomes in youth with type 1 diabetes. Diabetes Care 2013 Sep;36(9):2475-2482 [FREE Full text] [doi: 10.2337/dc12-2199] [Medline: 23579179]

30. Kumar S, Moseson H, Uppal J, Juusola JL. A diabetes mobile app with in-app coaching from a certified diabetes educator reduces A1C for individuals with type 2 diabetes. Diabetes Educ 2018 Jun;44(3):226-236. [doi: 10.1177/0145721718765650] [Medline: 29575982]

31. Mulvaney SA, Rothman RL, Wallston KA, Lybarger C, Dietrich MS. An internet-based program to improve self-management in adolescents with type 1 diabetes. Diabetes Care 2010 Mar;33(3):602-604 [FREE Full text] [doi: 10.2337/dc09-1881]

[Medline: 20032275]

32. Cafazzo JA, Casselman M, Hamming N, Katzman DK, Palmert MR. Design of an mHealth app for the self-management of adolescent type 1 diabetes: a pilot study. J Med Internet Res 2012 May 8;14(3):e70 [FREE Full text] [doi: 10.2196/jmir.2058] [Medline: 22564332]

33. Bin-Abbas B, Jabbari M, Al-Fares A, El-Dali A, Al-Orifi F. Effect of mobile phone short text messages on glycaemic control in children with type 1 diabetes. J Telemed Telecare 2014 Apr;20(3):153-156. [doi: 10.1177/1357633X14529244] [Medline: 24643953]

34. Roberts C, Sage A, Geryk L, Sleath B, Carpenter D. Adolescent preferences and design recommendations for an asthma self-management app: mixed-methods study. JMIR Form Res 2018 Sep 13;2(2):e10055 [FREE Full text] [doi: 10.2196/10055] [Medline: $\underline{30684424]}$

35. Spanakis EK, Golden SH. Race/ethnic difference in diabetes and diabetic complications. Curr Diab Rep 2013 Dec;13(6):814-823 [FREE Full text] [doi: 10.1007/s11892-013-0421-9] [Medline: 24037313]

36. Gaskin DJ, Thorpe RJ, McGinty EE, Bower K, Rohde C, Young JH, et al. Disparities in diabetes: the nexus of race, poverty, and place. Am J Public Health 2014 Nov;104(11):2147-2155 [FREE Full text] [doi: 10.2105/AJPH.2013.301420] [Medline: 24228660]

\section{Abbreviations \\ BMC: Boston Medical Center \\ HbA $_{1 \mathbf{c}}$ : hemoglobin $\mathrm{A}_{1 \mathrm{c}}$ \\ MDE: Mobile Diabetes Educator \\ T1D: type 1 diabetes \\ T2D: type 2 diabetes}

Edited by G Eysenbach; submitted 13.09.19; peer-reviewed by A Martinez-Millana, D Marais, V Traver Salcedo; comments to author
25.10.19; revised version received 02.12.19; accepted 10.02.20; published 01.05.20
Please cite as:
Otis M, Zhu J, Mustafa-Kutana SN, Bernier AV, Ma Shum J, Soros Dupre AA, Wang ML
Testing Usability and Feasibility of a Mobile Educator Tool for Pediatric Diabetes Self-Management: Mixed Methods Pilot Study
JMIR Form Res 2020;4(5):e16262
URL: $\underline{\text { https://formative.jmir.org/2020/5/e16262 }}$
doi: $\underline{10.2196 / 16262}$
PMID: $\underline{32356773}$

CMarisa Otis, Jack Zhu, Suleiman N Mustafa-Kutana, Angelina V Bernier, Julio Ma Shum, Arlette A Soros Dupre, Monica L Wang. Originally published in JMIR Formative Research (http://formative.jmir.org), 01.05.2020. This is an open-access article distributed under the terms of the Creative Commons Attribution License (https://creativecommons.org/licenses/by/4.0/), which permits unrestricted use, distribution, and reproduction in any medium, provided the original work, first published in JMIR Formative Research, is properly cited. The complete bibliographic information, a link to the original publication on http://formative.jmir.org, as well as this copyright and license information must be included. 